\title{
ANÁLISIS DE LAS MEDIDAS DE PROTECCIÓN A LOS DEFENSORES DE DERECHOS HUMANOS EN COLOMBIA, 2016-2019
}

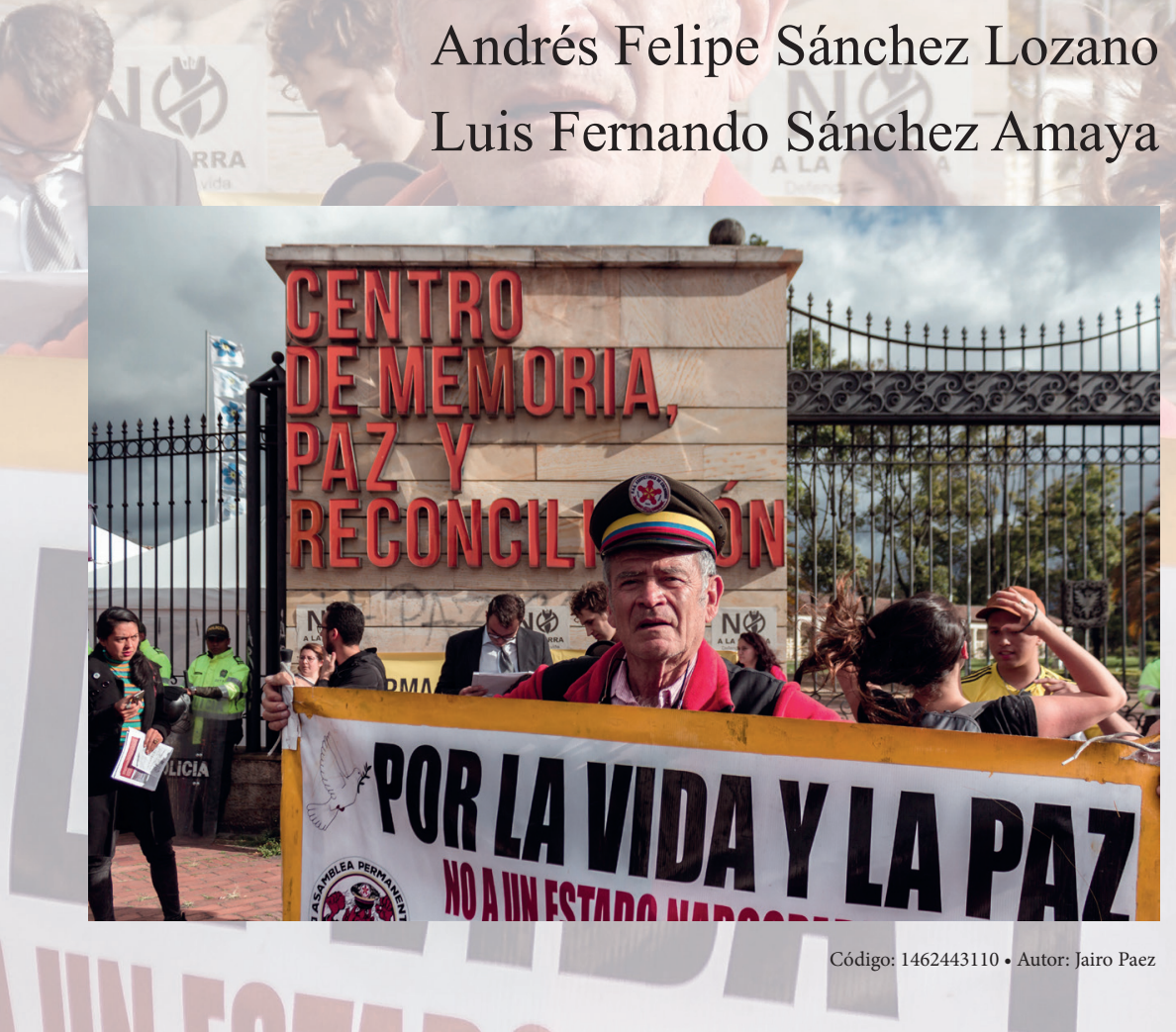





\title{
ANÁLISIS DE LAS MEDIDAS DE PROTECCIÓN A LOS DEFENSORES DE DERECHOS HUMANOS EN COLOMBIA, 2016-2019
}

\author{
Andrés Felipe Sánchez Lozano \\ Luis Fernando Sánchez Amaya \\ Universidad Católica de Colombia
}

\section{Resumen}

Es indudable que el trabajo de los defensores de derechos humanos en Colombia ha sido piedra angular para promover la protección a los derechos humanos y convencionales de las comunidades que, por una u otra razón, se han visto vulneradas; por este motivo, es fundamental que el Estado tenga la capacidad para proteger su actividad y garantizar que cualquier persona que pretenda atacar a quienes promueven los derechos humanos sea inmediatamente reducido y, de igual forma, el defensor sea cobijado por el manto institucional en relación con las garantías constitucionales, internacionales y convencionales.

Se vuelve prioritario puntualizar cuáles son las medidas de protección que cubren a los defensores de derechos humanos en Colombia y evidenciar la realidad que viven en ejercicio de sus actividades.

Palabras clave: defensor de derechos humanos, líderes sociales, obligaciones convencionales, Colombia, medidas de protección, Sistema Interamericano, Corte Interamericana, derechos humanos.

Los autores: Andrés Felipe Sánchez Lozano, estudiante de la Especialización en Derecho Constitucional. Auxiliar de investigación del Semillero de derechos humanos de la Universidad Católica de Colombia. Correo electrónico: afsl-94@hotmail.com

Luis Fernando Sánchez Amaya, estudiante de Derecho. Auxiliar de investigación del Semillero de derechos humanos de la Universidad Católica de Colombia. Correo electrónico: 1fsanchez02@ ucatolica.edu.co

Recibido: 13 de septiembre de 2019; evaluado: 16 de septiembre de 2019; aceptado: 18 de septiembre de 2019. 


\title{
ANALYSIS OF PROTECTION MEASURES FOR HUMAN RIGHTS DEFENDERS IN COLOMBIA, 2016-2019
}

\author{
Andrés Felipe Sánchez Lozano \\ Luis Fernando Sánchez Amaya \\ Catholic University of Colombia
}

\begin{abstract}
Doubtless, the work of human rights defenders in Colombia has been a cornerstone to promote the protection of the human and conventional rights of communities that for one reason or another have been violated. Thus, it is essential the State have the capacity to protect their activity and ensure that any person who attempts to attack those who promote human rights is immediately prevented from doing so, and likewise, the defender sheltered by the institutional mantle in relation with constitutional, international and conventional guarantees.
\end{abstract}

Therefore, it is a priority to specify the protection measures that cover human rights defenders in Colombia and to show the reality they face in the exercise of their activities.

Keywords: human rights defenders, social leaders, conventional obligations, Colombia, protection measures, Inter-American System, Inter-American Court, human rights.

About the authors: Andrés Felipe Sánchez Lozano, student of the Constitutional Law Specialization. Research assistant in the Human Rights Research Group of the Catholic University of Colombia. Email: afsl-94@hotmail.com

Luis Fernando Sánchez Amaya, law student. Research assistant in the Human Rights Research Group of the Catholic University of Colombia. Email: 1fsanchez02@ucatolica.edu.co

Received: September 13, 2019; evaluated: September 16, 2019; accepted: September 18, 2019. 


\title{
ANÁLISE DAS MEDIDAS DE PROTEÇÃO AOS DEFENSORES DOS DIREITOS HUMANOS NA COLÔMBIA, 2016-2019
}

\author{
Andrés Felipe Sánchez Lozano \\ Luis Fernando Sánchez Amaya \\ Universidad Católica de Colombia
}

\begin{abstract}
Resumo
Indubitavelmente, o trabalho dos defensores de Direitos Humanos dentro da Colômbia tem sido uma pedra angular para promover a proteção dos Direitos Humanos e convencionais de comunidades que, por uma razão ou outra, foram violados. Por esse motivo, é fundamental que o Estado tenha a capacidade de proteger sua atividade e garantir que qualquer pessoa que tenha intenção de atacar os que promovem os Direitos Humanos seja imediatamente limitada e, da mesma forma, que o defensor seja abrigado pelo manto institucional em correlação com garantias constitucionais, internacionais e convencionais.
\end{abstract}

Portanto, esclarecer as medidas de proteção que afetam os defensores dos Direitos Humanos na Colômbia e mostrar a realidade em que vivem no exercício de sua atividade é uma prioridade.

Palavras-chave: defensor dos Direitos Humanos, líderes sociais, obrigações convencionais, Colômbia, medidas de proteção, sistema interamericano, Corte Interamericana, Direitos Humanos.

Os autores: Andrés Felipe Sánchez Lozano, estudante de Especialização em Direito Constitucional. Auxiliar de pesquisa do grupo de pesquisa de Direitos Humanos da Universidad Católica de Colombia. E-mail: afsl-94@hotmail.com

Luis Fernando Sánchez Amaya, estudante de Direito. Auxiliar de pesquisa do grupo de pesquisa de Direitos Humanos da Universidad Católica de Colombia. E-mail: Ifsanchez02@ucatolica.edu.co

Recebido: 13 de setembro de 2019; avaliado: 16 de setembro de 2019; aceito: 18 de setembro de 2019. 


\section{Introducción}

Colombia ha sido una república violenta desde sus orígenes, pasando por el bipartidismo, el Bogotazo y la Violencia, y la fundación de grupos guerrilleros y paramilitares. La conformación de estos grupos, sumada al abandono de varias regiones del país, en especial, las regiones de periferia, desencadenó la vulnerabilidad de muchas personas, así como difíciles condiciones en el ejercicio de sus derechos, lo cual se reflejó en violaciones a la institucionalidad local y derechos como vida, integridad personal, propiedad, participación en la democracia, asociación y de reunión, entre otros.

En estas condiciones surge la figura del defensor de derechos humanos (en adelante, defensor de DDHH), como instrumento fundamental en la defensa de derechos colectivos en varios aspectos, con funciones que tienden al mejoramiento de condiciones de vida de las personas, a evitar la impunidad y a consolidar el Estado social de derecho.

No obstante, los diversos actores armados, en ejercicio de la fuerza y del poder obtenidos por métodos violentos, —en ocasiones con participación directa o indirecta de instituciones del Estado- han perpetrado toda clase de acciones hostiles en contra de ellos, por lo cual vale la pena indagar lo siguiente: ¿Las medidas de protección de defensores de DDHH han sido efectivas para garantizar el ejercicio de sus funciones?

El presente escrito se divide así: primero, se define al defensor de DDHH, su importancia y sus funciones; segundo, se establece el marco jurídico de protección del defensor de DDHH en Colombia; tercero, se examina la situación actual del defensor de DDHH durante el período 2016-2019 en el país; cuarto, se analizan las medidas de protección adoptadas por Colombia y, por último, se reflexiona sobre el tema planteado.

\section{Cuestiones preliminares}

\section{1. ¿Qué se entiende por defensores de derechos humanos?}

Aun cuando en los medios de comunicación y en la opinión abierta de la población civil, ajena al lenguaje técnico perteneciente de las ramas de estudios sociales como el derecho, la sociología o las ciencias políticas, se utiliza abiertamente el 
término defensor de derechos humanos o líderes y lideresas sociales defensores de los derechos humanos, no existe un precisión semántica suficiente respecto a lo que puede entenderse como defensor de los DDHH o si cualquier persona que persigue un bien común para una población general o un grupo específico puede catalogarse como tal.

Para dar un marco teórico, es necesario precisar el alcance conceptual del término global de defensor de DDHH. La Oficina del alto comisionado de Naciones Unidas para los Derechos Humanos (OACNUDH) ${ }^{1}$ ha expresado que el defensor de DDHH es la "persona que, individualmente o junto con otras, se esfuerza en [sic] promover o proteger esos derechos". ${ }^{2}$

Es un término válido desde la Declaración sobre los defensores de los derechos humanos de 1998, ${ }^{3}$ en la que se exhorta a los países miembros de la Organización de la Naciones Unidas (ONU) a proteger y preservar la actividad que ellos desarrollan, por su importancia para la consecución y materialización de los derechos humanos en todas las regiones del mundo.

En razón de lo anterior, cualquier persona que actúe para proteger los derechos humanos como pieza angular de la dignidad humana puede ser catalogada como defensor de DDHH, siempre y cuando su actividad sea continua; se divide en tres grandes grupos:

— Entidades gubernamentales: profesionales remunerados pertenecientes a alguna entidad del Estado que vela por la consolidación de los derechos humanos como parte de algún programa estatal, por ejemplo, la Agencia Nacional de Tierras. ${ }^{4}$

\footnotetext{
Organismo perteneciente a la Organización de la Naciones Unidas, encargado de proteger, preservar, promover y salvaguardar los derechos humanos en el mundo, bajo el mandato otorgado por los países para velar por el irreductible cumplimiento de los derechos humanos dentro de sus territorios. Oficina del alto comisionado de las Naciones Unidas para los derechos humanos, "¿Quiénes somos?", https://www.ohchr. org/sp/aboutus/Pages/WhoWeAre.aspx (acceso julio 16, 2018).

2 Oficina del alto comisionado de las Naciones Unidas para los derechos humanos, "Sobre los defensores de los derechos humanos", https://www.ohchr.org/sp/issues/srhrdefenders/pages/defender.aspx (acceso julio 16, 2018).

3 Organización de las Naciones Unidas [ONU], La Declaración de los defensores de los derechos humanos (Nueva York, 8 de marzo de 1999).

4 Parte del Ministerio de Agricultura y Desarrollo Rural para la consolidación y ejecución de la política de ordenamiento social de la propiedad rural. Agencia Nacional de Tierras, "La Agencia", http://www.agenciadetierras.gov.co (acceso julio 16, 2018).
} 
- Organizaciones no gubernamentales (ONG): profesionales o no profesionales, generalmente remunerados, que en nombre de alguna ONG actúan paralelamente al Estado, para que se valoren y garanticen a los derechos humanos, por ejemplo, Human Rights Watch. ${ }^{5}$

- Particulares: personas naturales que actúan en nombre propio o con el apoyo de una comunidad para proteger los derechos humanos de una región, de grupos específicos (indígenas, campesinos, etc.) o de un grupo de personas que comparten condiciones similares de vulneración, por ejemplo, Ana Teresa Yarce, en el caso Yarce y otras vs. Colombia. ${ }^{6}$

\subsection{Funciones de los defensores de derechos humanos}

Si bien no existe una lista taxativa que describa las tareas que desarrollan los defensores de DDHH, sí existen parámetros amplios frente a sus funciones en el ámbito regional, nacional o internacional, de manera que guardan cierta congruencia con la operatividad de los defensores de DDHH en todo el mundo.

Se ocupan de tareas como: i) promocionar y preservar los derechos humanos en zonas libres o con conflictos armados; ii) reunir y difundir información sobre violaciones de los derechos humanos; iii) apoyar a las víctimas de violaciones de los derechos humanos; iv) tomar medidas para garantizar la rendición de cuentas y el fin de la impunidad; v) apoyar a una política de gestión pública y de gobierno más eficaz; vi) contribuir a la aplicación de los tratados de derechos humanos, y vii) educar y capacitar en materia de derechos humanos. ${ }^{7}$

La figura del defensor de DDHH también ha sido abordada por la CIDH a partir de la labor que desempeñan las personas en un campo social específico, por lo cual se identifican grupos desde la situación de vulnerabilidad en la que se encuentran inmersos: i) líderes y lideresas sindicales; ii) defensores de derechos humanos propiamente dichos; iii) líderes y lideresas campesinos y comunitarios; iv) líderes y lideresas indígenas y afrodescendientes; v) defensores del derecho a un ambiente

5 Organización no gubernamental que vela por la defensa de los derechos humanos a escala internacional, así como su promoción en todos los países. Observatorio de Derechos Humanos, "Acerca de nosotros", https://www.hrw.org/es (acceso julio 16, 2018).

6 Corte Interamericana de Derechos Humanos, Caso Yarce y otras Vs. Colombia. Sentencia del 22 de noviembre de 2016.

7 Oficina del alto comisionado de las Naciones Unidas para los derechos humanos, Los defensores de los derechos humanos: protección del derecho a defender los derechos humanos (Nueva York: ONU, 2018), 3-7. 
sano; vi) líderes y lideresas de las personas LGTBI, y vii) defensores de los derechos de trabajadores migratorios. ${ }^{8}$

En consecuencia, con un espectro tan amplio, los campos de aplicación de las funciones de los defensores de DDHH no se limitan a un área específica, pues los derechos humanos son transversales. Asimismo, entre sus funciones resaltan:

[... f favorecer la reparación integral de las víctimas a través del esclarecimiento de los crímenes, el acercamiento a la verdad y el acceso a la justicia, reclamar una mayor redistribución de la riqueza y la propiedad de la tierra, y solicitar condiciones de seguridad para ejercer derechos sociales y políticos. ${ }^{9}$

\subsection{Importancia de los defensores de derechos humanos}

En los países americanos, los defensores de DDHH han cobrado vital importancia en las comunidades más apartadas de la presencia estatal, pues dan visibilidad a colectividades indígenas, campesinas y de víctimas de conflictos armados, así como a miembros de grupos LGBTI, entre otros. Su actividad radica en mostrar situaciones de injusticia social, combatir la impunidad e imponer a los Estados herramientas para la garantía de los derechos humanos de las poblaciones más vulnerables. ${ }^{10}$

Los defensores de DDHH se convierten en los vigías del cumplimiento del derecho interno y de las obligaciones en términos de derechos humanos, acogidas por un Estado y recuerdan además que:

[...] todos los miembros de la sociedad son responsables de velar por el respeto y la realización de los derechos humanos, puesto que la sociedad está obligada a reconocer a las víctimas y el Estado, mediante la justicia transicional [u ordinaria], a reconocerla moralmente y a rehabilitarla. ${ }^{11}$

8 Comisión Interamericana de Derechos Humanos, Segundo informe sobre la situación de las defensoras y los defensores de derechos humanos en las Américas (Washington: Organización de Estados Americanos, 2011), 103.

9 Xavier Mínguez Alcaide, "Conflicto y paz en Colombia. Significados en organizaciones defensoras de los derechos humanos", Revista de paz y conflictos 8, núm. 1 (2015): 193, https://dialnet.unirioja.es/descarga/ articulo/5117125.pdf (acceso julio 16, 2018).

10 Amnistía Internacional, "Defensores y defensoras de los derechos humanos", https://www.es.amnesty.org/ en-que-estamos/temas/defensores/ (acceso agosto 7, 2018).

11 Luis González León y Gilberto Ramírez, "Los derechos humanos de las víctimas: una perspectiva desde las responsabilidades del Estado y la sociedad civil" en Los derechos humanos a debate. Perspectivas desde el derecho internacional, ed. Gilberto Ramírez Huertas (Bogotá: Universidad Católica de Colombia, 2017), 106. 
En el ámbito estatal, el defensor del pueblo o quien haga sus veces, según el ordenamiento interno de cada país, se convierte en "un defensor de los DDHH de todos, individuos, grupos y pueblos, y particularmente, de acuerdo con el espíritu central de los derechos humanos, de los vulnerables, de aquellos más desvalidos, débiles o despojados". ${ }^{12}$

En la actualidad, la labor de los defensores de DDHH, líderes y lideresas sociales es fundamental para la operatividad y materialización de los derechos humanos. La Corte Interamericana de Derechos Humanos (Corte IDH) ha exhortado a los Estados miembros a no dejar los derechos humanos en el papel y cumplirlos desde un punto de vista formal, sino a adoptar todas las medidas necesarias para concretarlos, estos, mediante políticas que vuelvan tangible el derecho internacional de los derechos humanos. ${ }^{13}$

\section{4. ¿Deben ser protegidos los defensores de derechos humanos?}

Los defensores de DDHH en América Latina son objetivos tanto de los agentes del Estado como de grupos insurgentes, paramilitares y organizaciones criminales, que ven en estos sujetos un peligro para el desarrollo de actividades ilegales o de prácticas contrarias a los derechos inherentes a las comunidades, lo que lleva a campañas de difamación en su contra, así como malos tratos, amenazas de muerte, encarcelamientos arbitrarios, desaparición forzada, torturas y asesinatos. ${ }^{14}$

En el mismo sentido, la Comisión Interamericana de Derechos Humanos (CIDH) ha admitido que existe un problema generalizado en la región, pues los defensores de DDHH son usados para controlar poblaciones indígenas, afrodescendientes, desplazadas y cualquier comunidad vulnerable, ${ }^{15}$ frente las cuales, "si bien hay un proceso de inclusión y reconocimiento, también hay un proceso de exclusión e

12 Gonzalo Aguilar Cavallo y Rebecca Steward, "El defensor del pueblo latinoamericano como institución independiente de promoción y protección de los derechos humanos: referencia especial a la situación actual en Chile", Revista de derecho 15, núm. 2 (abril 2008): 31, https://www.redalyc.org/articulo.oa?id=371041323002 (acceso julio 16, 2018).

13 Corte Interamericana de Derechos Humanos, Caso Baena Ricardo y otros vs. Panamá. Sentencia del 28 de noviembre de 2003

14 Federación Internacional por los Derechos Humanos, "Defensores de derechos humanos", https://www. fidh.org/es/temas/defensores-de-derechos-humanos/ (acceso agosto 2, 2018).

15 Comisión Interamericana de Derechos Humanos, "Pronunciamiento de la Comisión Interamericana de derechos humanos sobre la aplicación y el alcance de la ley de justicia y paz en la República de Colombia", http://www.cidh.org/countryrep/Colombia2006sp/pronunciamiento.8.1.06esp.htm (acceso julio 16, 2018). 
invisibilización" ${ }^{16}$ por lo que la protección por parte de los Estados tiene un papel fundamental en la actividad de los defensores de DDHH.

Las personas más vulnerables de cualquier población acuden a los defensores como un mecanismo para limitar los abusos de poder estatal ${ }^{17}$ y repeler el accionar criminal de grupos insurgentes que atacan los intereses colectivos de una comunidad. De esta forma, el defensor de DDHH exige al Estado social de derecho el reconocimiento de la dignidad humana, sus derechos y libertades. ${ }^{18}$

\section{Marco jurídico de protección a los defensores de derechos humanos en Colombia}

Consecuente con la responsabilidad derivada de las obligaciones producto de la $\mathrm{CADH},{ }^{19}$ en particular del Artículo 2, que exhorta a los Estados parte a adoptar disposiciones en al ámbito interno para que se materialicen en la práctica, Colombia ha adoptado mandatos legales para intentar proteger a los defensores de DDHH en la jurisdicción interna.

En esta misma línea conceptual se sostiene que:

[...] para la comunidad internacional, es relevante que los Estados diseñen su política interna y externa de acuerdo con los estándares internacionales de protección de los derechos humanos. Dichos estándares se constituyen, por un lado, en pautas mínimas de comportamiento y, por otro, establecen

16 Karina Ansolabehere y Luis Daniel Vásquez, "De la injusticia a los derechos: momentos en la construcción de identidad de defensores de derechos humanos. El caso de México", Estudios sociológicos 35, núm. 105 (septiembre-diciembre 2017): 522, http://www.scielo.org.mx/pdf/es/v35n105/2448-6442-es-35-105-0517. pdf (acceso julio 16, 2018).

17 Jairo Antonio López, "Movilización y acción colectiva por los derechos humanos en la paradoja de la institucionalización", Estudios políticos, núm. 51 (julio-diciembre 2017): 65, https://www.redalyc.org/articulo. oa?id=16452081004 (acceso julio 16, 2018).

18 Andrés Felipe Roncancio Bedoya, Víctor Julián Moreno Mosquera y Pablo Daniel Hurtado Quintero, "El papel del defensor de derechos humanos como parresiasta: desafíos para la construcción de paz en el proceso de finalización del conflicto armado en Colombia", Vía Iuris, núm. 21 (julio-diciembre 2016): 172, https:// www.redalyc.org/pdf/2739/273950435010.pdf (acceso julio 16, 2018).

19 Organización de los Estados Americanos [OEA], Convención americana de derechos humanos (San José, 22 de noviembre de1969), art. 2. 
obligaciones a los Estados de investigar y sancionar las violaciones de los derechos humanos, así como de proteger y reparar a todas las víctimas. ${ }^{20}$

Por ello, se hace indispensable analizar las medidas de protección de los defensores de DDHH en el marco jurídico colombiano, y sus obligaciones convencionales, para determinar si la compilación normativa nacional es coherente con el control de convencionalidad producto de la jurisprudencia de la Corte IDH. ${ }^{21}$

\subsection{Marco legislativo y normativo para la protección de defensores de derechos humanos}

La Constitución Política, la norma superior, denomina a Colombia como Estado social de derecho, lo cual trae dos implicaciones fundamentales: "(i) el reconocimiento de los derechos humanos como eje transversal de todas las políticas y programas del Estado y, (ii) la creación de mecanismos de protección inmediata que prevengan violaciones y protejan los derechos humanos". 22

De esta manera, como un faro para la promulgación de leyes, decretos o normas en cuanto a protección a defensores de DDHH, ha de tenerse en cuenta lo expresado por los artículos siguientes (Tabla 1):

Tabla 1. Ejes constitucionales para defensores de derechos humanos

\begin{tabular}{|l|l|}
\hline Artículo 1 & Colombia es un Estado social de derecho. \\
\hline Artículo 2 & Fines esenciales del Estado. \\
\hline Artículo 5 & Primacía de los derechos inalienables de la persona. \\
\hline Artículo 7 & Reconoce y protege la diversidad étnica y cultural de la Nación. \\
\hline Artículo 11 & El derecho a la vida es inviolable. \\
\hline Artículo 12 & $\begin{array}{l}\text { Nadie será sometido a desaparición forzada, torturas ni tratos o penas crueles, inhumanos o } \\
\text { degradantes. }\end{array}$ \\
\hline Artículo 13 & Todas las personas nacen libres e iguales ante la ley. \\
\hline Artículo 14 & Toda persona tiene derecho al reconocimiento de su personalidad jurídica. \\
\hline Artículo 18 & Se garantiza la libertad de conciencia. \\
\hline
\end{tabular}

20 Jaime Cubides Cárdenas y Tania Giovanna Vivas Barrera, "La justicia transicional y el rol de la Corte Interamericana de Derechos Humanos" en Fundamentación y aplicabilidad de la justicia transicional en Colombia, ed. Jaime Cubides Cárdenas (Bogotá: Universidad Católica de Colombia, 2016), 69.

21 Corte Interamericana de Derechos Humanos, Control de convencionalidad: cuadernillo de jurisprudencia de la Corte Interamericana de Derechos Humanos No. 7 (San José: OEA, 2015), 1-25.

22 Programa Somos Defensores, Un canto final: manual de protección para defensores y defensoras de derechos humanos en Colombia (Bogotá: Alta Voz Ediciones 2010), 21. 


\begin{tabular}{|l|l|}
\hline Artículo 20 & Se garantiza a toda persona la libertad de expresar y difundir su pensamiento y opiniones. \\
\hline Artículo 22 & La paz como un derecho y un deber de obligatorio cumplimiento. \\
\hline Artículo 26 & Toda persona es libre de escoger profesión u oficio. \\
\hline Artículo 28 & Toda persona es libre. \\
\hline Artículo 95 & $\begin{array}{l}\text { El ejercicio de los derechos y libertades reconocidos en la Constitución Política implica res- } \\
\text { ponsabilidades, entre ellas, propender al logro y mantenimiento de la paz; de igual manera, } \\
\text { establece en su numeral 4 el deber de las personas y los ciudadanos de defender y difundir } \\
\text { los derechos humanos como fundamento de la convivencia pacífica. }\end{array}$ \\
\hline
\end{tabular}

Fuente: elaboración propia con base en República de Colombia, Constitución Politica (Bogotá: Legis, 1991).

\section{Con base en lo anterior, se ha expedido el siguiente marco legislativo y normativo para la protección de todos los defensores de DDHH en el territorio colombiano (Tabla 2):}

Tabla 2. Marco legal nacional para la protección de defensores de derechos humanos

\begin{tabular}{|l|l|}
\hline Ley 418 de $1997^{23}$ & $\begin{array}{l}\text { Creó las bases para los programas de protección a defensores de } \\
\text { DDHH y determinó los grupos de personas que serían objeto de } \\
\text { protección especial. }\end{array}$ \\
\hline Decreto 978 de $2000^{24}$ & $\begin{array}{l}\text { Creó el programa de protección a militantes y dirigentes políticos } \\
\text { de oposición. }\end{array}$ \\
\hline Decreto 1592 de $2000^{25}$ & Instauró el programa de protección a periodistas y comunicadores. \\
\hline Decreto 1386 de $2002^{26}$ & Creó el programa de protección a alcaldes, concejales y personeros. \\
\hline Decreto 2788 de $2003^{27}$ & $\begin{array}{l}\text { Conformó el programa de protección a personas y grupos en situación } \\
\text { de riesgo por causas políticas. }\end{array}$ \\
\hline
\end{tabular}

23 Congreso de la República de Colombia, Ley 418 de 1997, "Por la cual se consagran unos instrumentos para la búsqueda de la convivencia, la eficacia de la justicia y se dictan otras disposiciones" (Bogotá: Diario Oficial núm. 43.201, 26 de diciembre de 1997).

24 Colombia, Presidencia de la República, Decreto 978 de 2000, "Por el cual se crea el Programa especial de protección integral para dirigentes, miembros y sobrevivientes de la Unión Patriótica y del Partido Comunista Colombiano" (Bogotá: Diario Oficial núm. 44.033, 1 de junio de 2000).

25 Colombia, Presidencia de la República, Decreto 1592 de 2000, "Por el cual se reglamenta el artículo 6 de la Ley 199 de 1995" (Bogotá: Diario Oficial núm. 44.139, 18 de agosto de 2000).

26 Colombia, Presidencia de la República, Decreto 1386 de 2002, "Por el cual el cual se dictan medidas para brindar protección a alcaldes, concejales y personeros municipales" (Bogotá: Diario Oficial núm. 44.861, 10 de julio de 2002).

27 Colombia, Presidencia de la República, Decreto 2788 de 2003, "Por el cual se unifica y reglamenta el Comité de reglamentación y evaluación de riesgos de los programas de protección de la dirección de derechos humanos del Ministerio del Interior y de Justicia" (Bogotá: Diario Oficial núm. 45.329, 2 de octubre de 2003). 


\begin{tabular}{|l|l|}
\hline Decreto 660 de $2018^{28}$ & $\begin{array}{l}\text { Creó y reglamentó el Programa integral de seguridad y protección para } \\
\text { las comunidades y organizaciones en los territorios, con el propósito } \\
\text { de definir y adoptar medidas de protección integral para las mismas } \\
\text { en los territorios, incluidos líderes, lideresas, dirigentes, representantes } \\
\text { yactivistas de organizaciones sociales, populares, étnicas, de mujeres, } \\
\text { de género, ambientales, comunales, de los sectores LGBTI y defensores } \\
\text { de DDHH en los territorios. }\end{array}$ \\
\hline Directiva Presidencial 07 de $1999^{29}$ & Sobre la protección a organizaciones de derechos humanos. \\
\hline Directiva Ministerial 09 de $2003^{30}$ & Sobre protección a sindicalistas y defensores de derechos humanos. \\
\hline $\begin{array}{l}\text { Circular Externa del Ministerio del } \\
\text { Interior CRI 01 } 01^{31}\end{array}$ & $\begin{array}{l}\text { Garantías para la labor que desempeñan en el país defensores y defen- } \\
\text { soras de derechos humanos, así como líderes sociales y comunales. }\end{array}$ \\
\hline
\end{tabular}

Fuente: elaboración propia

Aunado a lo anterior, el Estado colombiano tiene garantías especiales de obligatorio cumplimiento, en virtud del Acuerdo para la terminación del conflicto y la construcción de una paz estable y duradera, firmado en 2016. ${ }^{32}$

El Acuerdo dispone:

Garantías de seguridad y lucha contra las organizaciones y conductas criminales responsables de homicidios y masacres, que atentan contra defensores/as de DDHH, movimientos sociales o movimientos políticos o que amenacen o atenten contra las personas que participen en la implementación de los acuerdos y la construcción de la paz, incluyendo las organizaciones criminales que hayan sido denominadas como sucesoras del paramilitarismo y sus redes de apoyo. ${ }^{33}$

Este fundamento para la implementación de políticas como el Decreto 066 de 2018 y, de esta manera, el Acuerdo de paz se convierte en un bastión para la protección de los defensores de DDHH.

28 Colombia, Presidencia de la República, Decreto 660 de 2018, "Por el cual se adiciona el Capítulo 7, del Título 1, de la Parte 4, del Libro 2 del Decreto 1066 de 2015, Único Reglamentario del Sector Administrativo del Interior, para crear y reglamentar el Programa integral de seguridad y protección para comunidades y organizaciones en los territorios; y se dictan otras disposiciones" (Bogotá: Diario Oficial núm. 50.567, 17 de abril de 2018).

29 Colombia, Presidencia de la República, Directiva presidencial 07 de 1999 (Bogotá, 9 de septiembre de 1999).

30 Colombia, Ministerio de Defensa Nacional, Directiva ministerial 09 de 2003 (Bogotá, 8 de julio de 2003).

31 Colombia, Ministerio del Interior, Circular CRI01 de 2018 (Bogotá, 4 de agosto de 2018).

32 Gobierno Nacional y Fuerzas Armadas Revolucionarias de Colombia-Ejército del Pueblo, Acuerdo final para la terminación del conflicto y la construcción de una paz estable y duradera (Bogotá, 24 de noviembre de 2016).

33 Gobierno Nacional y Fuerzas Armadas Revolucionarias de Colombia-Ejército del Pueblo, Acuerdo final para la terminación del conflicto. 
Producto de los acuerdos mencionados y como un nuevo estamento para la protección de los derechos de los más vulnerables, la Ley 1957 de 2011, denominada Ley estatutaria de la administración de justicia en la jurisdicción especial para la paz (aún en proceso de implementación), ha consagrado los derechos de las víctimas en el marco de los procesos judiciales que se adelanten ante esa jurisdicción, en el marco de las garantías de verdad, justicia, reparación y garantías de no repetición, ${ }^{34}$ lo cual se debe entender a la luz del plazo razonable y los parámetros fijados por la Corte IDH. ${ }^{35}$

\subsection{Entidades estatales que protegen a los defensores de derechos humanos en Colombia}

No basta con que exista un marco normativo como el expuesto en el acápite anterior, si no está respaldado por entidades gubernamentales que avalen y controlen las vulneraciones a los derechos de defensores de DDHH. Es primordial que el Estado comprenda que "la imparcialidad y la transparencia son esenciales, y para los defensores de los DDHH la igualdad de trato ante la ley y la integridad de las agencias de aplicación de la ley son elementos indispensables". ${ }^{36}$

Por eso, en el ordenamiento orgánico de Colombia se han creado instituciones estatales jurídicamente reconocidas para que protejan a los defensores de DDHH dentro del territorio nacional. Estos organismos son (Tabla 3):

Tabla 3. Entidades constitucionales para la protección de los defensores de derechos humanos

\begin{tabular}{|l|l|}
\hline Defensoría del Pueblo & $\begin{array}{l}\text { Se encarga de defender y promover los derechos humanos de todos los } \\
\text { ciudadanos. Está adscrita al Ministerio Público y, por lo tanto, forma } \\
\text { parte de los organismos de control del Estado. }\end{array}$ \\
\hline Procuraduría General de la Nación & $\begin{array}{l}\text { Vigila que se cumpla la Constitución y que se apliquen las leyes, las } \\
\text { decisiones judiciales y los actos administrativos. Debe velar por los } \\
\text { derechos humanos y defender los intereses de la sociedad. }\end{array}$ \\
\hline
\end{tabular}

34 Congreso de la República de Colombia, Ley 1957 de 2019, "Estatutaria de la Administración de Justicia en la Jurisdicción Especial para la Paz" (Bogotá: Diario Oficial núm. 50.976, 6 de junio de 2019).

35 Nathalia María Chacón Triana, Acceso al Sistema Interamericano de Derechos Humanos. Perspectiva jurisprudencial (Bogotá: Ibáñez, 2018), 284-285.

36 Oscar Vilhena Vieira, "La desigualdad y la subversión del Estado de derecho", SUR. Revista internacional de derechos humanos 4, núm. 6 (2007): 34, http://www.scielo.br/pdf/sur/v4n6/es_a03v4n6.pdf (acceso julio $16,2018)$. 


\begin{tabular}{|l|l|}
\hline Personería Municipal & $\begin{array}{l}\text { Ejerce el control administrativo en la ciudad. Le corresponden la defensa } \\
\text { y la promoción de los derechos humanos, la protección del interés } \\
\text { público y la vigilancia de la conducta oficial de quienes desempeñan } \\
\text { funciones públicas en la ciudad. }\end{array}$ \\
\hline Fiscalía General de la Nación & $\begin{array}{l}\text { Organismo titular de la acción penal. Investiga y acusa a los respon- } \\
\text { sables de cometer conductas que atenten contra bienes jurídicamente } \\
\text { protegidos, tipificados como delitos. }\end{array}$ \\
\hline Ministerio del Interior & $\begin{array}{l}\text { Ejercer la rectoría y la coordinación de las políticas públicas para el } \\
\text { fortalecimiento de la democracia, la convivencia y la participación } \\
\text { ciudadana y garantizar el disfrute de los derechos y libertades públicas, } \\
\text { así como el ejercicio pleno del Estado social de derecho. }\end{array}$ \\
\hline
\end{tabular}

Fuente: elaboración propia

Las entidades descritas tienen la obligación constitucional de tomar medidas concretas ante las amenazas contra defensores de DDHH y así mitigar sus riesgos.

\section{Situación de los defensores de derechos humanos en Colombia (2016-2019)}

Históricamente, el contexto social y político de la sociedad colombiana ha estado marcado por la permanente existencia de un conflicto armado. En el Sistema Interamericano, Colombia tiene obligaciones internacionales especiales que deben ser atendidas, ${ }^{37}$ de allí que la labor de los defensores de DDHH cobra una vital importancia para reclamar los derechos que han sido vulnerados durante décadas.

Una vez examinada la protección que otorgan la Constitución, los tratados y convenios internacionales ratificados por Colombia, el marco legal vigente y las instituciones estatales encargadas de la seguridad y la garantía de derechos del defensor de DDHH, se expondrá la situación actual de estas personas desde la fecha de la firma de los Acuerdos de $\mathrm{Paz}^{38}$ (24 de noviembre de 2016) hasta el 26 de julio de 2019. El análisis se desarrollará teniendo en cuenta que las fechas establecidas pueden presentar variaciones, toda vez que la presentación de informes estadísticos entregados por instituciones estatales puede sobrepasar las fechas estipuladas en

37 Sandra Montoya Ruiz, John Castro Ortiz y Jaime Cubides Cárdenas, "Elementos jurídicos y de legitimación para acuerdos de paz con miras al posconflicto" en Desafíos contemporáneos de la protección de los derechos humanos en el Sistema Interamericano, ed. Jaime Cubides Cárdenas (Bogotá: Universidad Católica de Colombia, 2017), 89.

38 Gobierno Nacional y Fuerzas Armadas Revolucionarias de Colombia-Ejército del Pueblo, Acuerdo final para la terminación del conflicto. 
este escrito. Se expone una revisión estadística, basada en informes de organismos estatales e internacionales, y de organizaciones no gubernamentales.

Con base en la información oficial de la Defensoría del Pueblo, se tiene que entre el 1 de enero de 2016 y el 31 de agosto de 2018 se registraron 431 homicidios contra líderes sociales y defensores de DDHH, clasificados de la siguiente manera (Tabla 4): ${ }^{39}$

Tabla 4. Homicidios contra líderes sociales y defensores de DDHH por departamentos

\begin{tabular}{|c|c|c|c|}
\hline Departamento & Casos de homicidio & Departamento & Casos de homicidio \\
\hline Cauca & 106 & Tolima & 7 \\
\hline Antioquia & 61 & Atlántico & 5 \\
\hline Norte de Santander & 31 & Caldas & 5 \\
\hline Valle del Cauca & 28 & Magdalena & 5 \\
\hline Nariño & 21 & Casanare & 4 \\
\hline Chocó & 20 & Huila & 4 \\
\hline Putumayo & 18 & Santander & 4 \\
\hline Caquetá & 16 & Bogotá & 3 \\
\hline Meta & 15 & La Guajira & 2 \\
\hline Arauca & 14 & Guaviare & 2 \\
\hline Córdoba & 14 & Quindío & 2 \\
\hline Risaralda & 13 & Boyacá & 1 \\
\hline Bolívar & 10 & Sucre & 1 \\
\hline Cundinamarca & 10 & Vichada & 1 \\
\hline Cesar & 8 & Total & 431 \\
\hline
\end{tabular}

Fuente: elaboración propia

La Tabla 4 muestra el grado de vulnerabilidad que, en términos generales, padecen las personas defensoras y líderes sociales de los departamentos de la región Pacífica, Norte de Santander y Antioquia, lo cual permite identificar un riesgo elevado de ataque por parte de diferentes organizaciones armadas ilegales, patrón que se repite, como se evidencia más adelante.

Según la Oficina del alto comisionado de Naciones Unidas para los derechos humanos (en adelante, OACNUDH), en 2016, cuando culminaron las negociaciones entre

39 Carlos Alfonso Negret Mosquera, "El riesgo de los defensores de derechos humanos merece mayor atención del Estado", http://www.defensoria.gov.co/es/nube/comunicados/7716/\%E2\%80\%9CEl-riesgo-de-losdefensores-de-derechos-humanos-merece-mayor-atenci\%C3\%B3n-del-Estado\%E2\%80\%9D-DefensorDefensor-del-Pueblo-Carlos-Negret-Defensor\%C3\%ADa-derechos-humanos.htm (acceso julio 16, 2018). 
el Gobierno y las FARC, se registraron 389 ataques contra defensores de DDHH, clasificados así (Tabla 5):40

Tabla 5. Ataques contra defensores de derechos humanos

\begin{tabular}{|l|c|}
\hline Tipo de agresión & Número de casos \\
\hline Homicidios & 59 \\
\hline Ataques & 44 \\
\hline Amenazas & 210 \\
\hline Violaciones al derecho de propiedad y privacidad & 72 \\
\hline Desapariciones forzadas & 3 \\
\hline Violencia sexual & 1 \\
\hline
\end{tabular}

Fuente: elaboración propia

No obstante, estas cifras no coinciden con las que presenta el programa Somos Defensores ${ }^{41}$ por medio del Sistema de información sobre agresiones contra defensores de derechos humanos en Colombia (en adelante, SIADDHH), toda vez que el número de ataques contra líderes y defensores asciende a 481 casos; de ellos, 80 correspondieron a homicidios y 49, a atentados. Del total de casos, 326 fueron cometidos contra hombres (67,8\%) y 155 contra mujeres (32,3\%). De los 481 casos registrados por esta organización, 62 ocurrieron en los meses de noviembre y diciembre; 16 de ellos fueron homicidios.

Para el año 2017, cuando comenzaban los procesos de implementación de los Acuerdos de Paz, la OACNUDH mostró profunda preocupación por la situación en la que se encontraban los defensores de DDHH, toda vez que las zonas que habitaron las FARC-EP durante sus actividades subversivas comenzaron a ser ocupadas por otros grupos armados al margen de la ley, lo que generó un entorno más violento, en razón a la dilatada implementación de los Acuerdos y a los

40 Oficina del alto comisionado de las Naciones Unidas para los derechos humanos, Informe del alto comisionado de las Naciones Unidas para los derechos humanos sobre la situación de derechos humanos en Colombia durante el año 2016 (Bogotá: OACNUDH, 2017), 10.

41 Es un programa de la organización no gubernamental de protección a defensores de derechos humanos en Colombia "Somos Defensores", la cual se encarga de visibilizar los casos de ataques a los defensores de DDHH en informes periódicos entregados al Gobierno nacional, a las entidades interesadas y a la opinión pública. Programa Somos Defensores, Contra las cuerdas: informe anual 2016. Sistema de información sobre agresiones contra defensores de DDHH en Colombia SIADDHH (Bogotá: Factoría Gráfica, 2017), 25-34. 
intereses económicos y territoriales de los demás grupos. Las cifras emitidas por la OACNUDH son (Tabla 6):42

Tabla 6. Tipos y cantidad de ataques a defensores de derechos humanos posteriores a 2017

\begin{tabular}{|l|c|}
\hline Tipo de agresión & Número de casos \\
\hline Homicidio contra defensores de DDHH que ejercían liderazgo & 84 \\
\hline Miembros de movimientos sociales y políticos & 23 \\
\hline Personas muertas durante protestas sociales & 14 \\
\hline Ataques (intentos de homicidio) & 41 \\
\hline Amenazas & 213 \\
\hline Violaciones al derecho de propiedad y privacidad & 61 \\
\hline Desapariciones forzadas & 4 \\
\hline Violencia sexual & 1 \\
\hline Total de ataques & 441 \\
\hline
\end{tabular}

Fuente: elaboración propia

Los homicidios registrados por la OACNUDH corresponden a 80 personas; sin embargo, el programa Somos defensores, por medio del SIADDHH, ha indicado que el número de ataques en contra de los defensores de derechos humanos es superior al indicado por la OACNUDH, pues se registraron 560 casos, de los cuales 106 corresponden a homicidios y 50 a atentados. Del total de casos: 417 se cometieron contra hombres (74,46 \%) y 143 en contra de mujeres $(25,54 \%) .{ }^{43}$ Un dato relevante con respecto al número de homicidios que difiere del reportado por el SIADDHH es el entregado por Amnistía Internacional, que calcula 105 homicidios contra defensores de DDHH, focalizados en líderes comunitarios, defensores del derecho a la tierra (incluso indígenas y afrodescendientes), del territorio y del ambiente, y de quienes durante su activismo apoyaron el proceso de paz con las FARC-EP. ${ }^{44}$

42 Oficina del alto comisionado de las Naciones Unidas para los derechos humanos, Informe del alto comisionado de las Naciones Unidas para los derechos humanos sobre la situación de derechos humanos en Colombia durante el año 2017 (Bogotá: OACNUDH, 2018), 3.

43 Programa Somos Defensores, Piedra en el zapato: informe anual 2017 sistema de información sobre agresiones contra defensores y defensoras de DDHH en Colombia (Bogotá: Cimaz, 2018), 59-61.

44 Amnistía Internacional, Informe 2017/2018 Amnistía Internacional: la situación de derechos humanos en el mundo (Londres: Amnistía Internacional, 2018), 158. 
Según la fundación Heinrich Böll, desde el 1 de enero hasta el 14 de mayo de 2018 se presentaron 78 homicidios contra líderes sociales, de los cuales 50 se cometieron en los siguientes departamentos: 15 en Cauca; 12 en Antioquia; 8 en Norte de Santander; 5 en Nariño; 5 en Córdoba; 4 en Chocó y 1 en Valle del Cauca. ${ }^{45}$

Somos Defensores presentó como consolidado, durante el año en mención, la cifra de 155 personas asesinadas, repartida como sigue: 63 líderes comunales; 24 líderes indígenas; 24 líderes comunitarios; 19 líderes campesinos; 7 líderes sindicales; 6 líderes afrocolombianos; 3 líderes de víctimas; 3 líderes educativos; 3 líderes pro restitución de tierras; 2 defensores del ambiente y 1 líder perteneciente a la población LGTBI. ${ }^{46}$ Como puede observarse, dicha división obedece a los estándares que ha fijado la CIDH para clasificar a los defensores de DDHH, de conformidad al campo en el que se desempeñan, como se explicó con antelación.

En el año 2019, según Indepaz, desde el 1 de enero hasta el 26 de julio se presentaron 112 homicidios contra líderes sociales y defensores de derechos humanos. Del consolidado parcial se tiene que 82 homicidios tuvieron lugar en los departamentos de Cauca (21), Valle del Cauca (15), Nariño (14), Antioquia (12), Córdoba (9), Norte de Santander (7) y Putumayo (3). ${ }^{47}$ Lo anterior no es otra cosa que la comprobación de que los lugares o las zonas del país donde se cometen acciones hostiles contra defensores de derechos humanos suelen ser las mismas cada año.

Para concluir este acápite, cabe mencionar que la identificación de autores y partícipes en la comisión de estas conductas ha sido difícil, habida cuenta de que el territorio se ha reconfigurado para las acciones ilegales, de la reorganización de los grupos ilegales —entre ellos, los grupos disidentes de las FARC-EP, los paramilitares y las bandas criminales - de las nuevas tendencias del narcotráfico a escala mundial y del control del territorio propiamente dicho. ${ }^{48}$

45 Fundación Heinrich Böll, "Informe especial de derechos humanos: situación de lideresas y líderes sociales, de defensoras y defensores de derechos humanos y de excombatientes de las FARC-EP y sus familiares", Ideas verdes, núm. 8 (junio 2018): 15, https://co.boell.org/sites/default/files/20180629_ideas_verdes_8_web. ok_.pdf (acceso julio 16, 2018).

46 Programa Somos Defensores, La naranja mecánica: informe anual 2018 sistema de información sobre agresiones contra personas defensoras de derechos en Colombia SIADDHH (Bogotá: El búho, 2019), 91-92.

47 Instituto de Estudios para el Desarrollo y la Paz, Informe líderes y defensores de DDHH asesinados al 26 de julio de 2019 (Bogotá, 23 de julio de 2019), 10-12.

48 Colombia, Procuraduría General de la Nación, Violencia contra los defensores de derechos territoriales en Colombia (Bogotá: Autor, 2018), 78-79. 


\section{Medidas adoptadas por Colombia para la protección de los defensores de derechos humanos}

Luego de aclarar el contexto jurídico internacional y nacional, es preciso analizar las medidas adoptadas por Colombia, toda vez que es en este eslabón donde se generan las garantías suficientes para proteger a los defensores de DDHH en cualquier Nación. Dadas las obligaciones institucionales derivadas de la normatividad interna y las obligaciones convencionales, surge la pertinencia de la ejecución de políticas y programas que protejan a ese grupo.

La Corte IDH se ha manifestado para exhortar a los Estados parte a introducir en la jurisdicción interna la adecuación de normas y prácticas estatales como un deber al ratificar la $\mathrm{CADH}^{49}$ y, asimismo, el Estado colombiano tiene la "obligación de garantizar de manera prioritaria e integral los derechos de los defensores de derechos humanos". 50

De esta manera, en cabeza del Ministerio de Interior recae la función de:

Diseñar e implementar, de conformidad con la Ley, las políticas públicas de protección, promoción, respeto y garantía de los Derechos Humanos [...] así como la prevención a las violaciones de estos y la observancia al Derecho Internacional Humanitario, con un enfoque integral, diferencial y social. ${ }^{51}$

Por consiguiente, esta entidad ha adelantado los programas para la protección de líderes sociales y defensores de derechos humanos en el territorio colombiano, con los siguientes programas y políticas de amparo (Tabla 7):

Corte Interamericana de Derechos Humanos, Caso Cinco pensionistas Vs. Perú. Sentencia del 28 de febrero de 2003.

50 Magda Paola Tafur Charry, "El precedente jurisprudencial" en Precedente jurisprudencial en materia de justicia transicional, ed. Magda Paola Tafur Charry (Bogotá: Universidad Católica de Colombia, 2016), 68.

51 Congreso de la República de Colombia, Ley 489 de 1998, "Por la cual se dictan normas sobre la organización y funcionamiento de las entidades del orden nacional, se expiden las disposiciones, principios y reglas generales para el ejercicio de las atribuciones previstas en los numerales 15 y 16 del artículo 189 de la Constitución Política y se dictan otras disposiciones" (Bogotá: Diario Oficial núm. 43.464, 30 de diciembre de 1998), art. 59. 
Tabla 7. Programas y politicas de amparo para la protección de líderes sociales $y$ defensores de derechos humanos

\begin{tabular}{|c|c|}
\hline Ley 418 de $1997^{52}$ & $\begin{array}{l}\text { Establece que se pondrá en funcionamiento un programa de protección a } \\
\text { personas que se encuentren en situación de riesgo contra su vida, integridad, } \\
\text { seguridad o libertad, por causas relacionadas con la violencia política o ideo- } \\
\text { lógica, o con el conflicto armado interno que padece el país. }\end{array}$ \\
\hline $\begin{array}{l}\text { Programa general de protección } \\
\text { de la Dirección de Derechos } \\
\text { Humanos }^{53}\end{array}$ & $\begin{array}{l}\text { Dirigido a proteger a las personas que promocionan los derechos humanos en } \\
\text { Colombia, así como a las entidades encargadas de esta tarea. }\end{array}$ \\
\hline $\begin{array}{l}\text { Resolución } 2138 \text { del Ministerio } \\
\text { del Interior }{ }^{54}\end{array}$ & $\begin{array}{l}\text { Definiciones, usos y procedimientos de las medidas del Programa de protección } \\
\text { de derechos humanos. }\end{array}$ \\
\hline $\begin{array}{l}\text { Sistema nacional de derechos } \\
\text { humanos y derecho interna- } \\
\text { cional humanitario }\end{array}$ & $\begin{array}{l}\text { Coordina las normas, políticas, entidades e instancias del orden nacional y } \\
\text { territorial para promover el respeto y la garantía de los derechos humanos y } \\
\text { la aplicación del derecho internacional humanitario. }\end{array}$ \\
\hline Decreto 4065 de $2011^{56}$ & $\begin{array}{l}\text { Se creó la Unidad Nacional de Protección (UNP). Su objeto es articular, coor- } \\
\text { dinar y ejecutar la prestación del servicio de protección a quienes determine } \\
\text { el Gobierno nacional, cuyas actividades, condiciones o situaciones políticas, } \\
\text { públicas, sociales, humanitarias, culturales, étnicas o de género o sus calida- } \\
\text { des de víctima de la violencia de desplazamiento o de activistas de derechos } \\
\text { humanos, los pongan en situación de riesgo extraordinario o extremo de sufrir } \\
\text { daños contra su vida, integridad, libertad y seguridad personal. Cubre también } \\
\text { a quienes ejercen un cargo público u otras actividades que conllevan riesgo } \\
\text { extraordinario, como el liderazgo sindical, de ONG y de grupos de personas } \\
\text { desplazadas. Asimismo, garantiza la oportunidad, eficiencia e idoneidad de } \\
\text { las medidas que se otorgan. }\end{array}$ \\
\hline Decreto 4912 de $2011^{57}$ & $\begin{array}{l}\text { Programa de prevención y protección de los derechos a la vida, la libertad, la } \\
\text { integridad y la seguridad de personas, grupos y comunidades. }\end{array}$ \\
\hline $\begin{array}{l}\text { Decreto único reglamentario } \\
\text { del sector administrativo del } \\
\text { interior }^{58}\end{array}$ & $\begin{array}{l}\text { Normatividad vigente que regula protección a las actividades de los defen- } \\
\text { sores de DDHH. }\end{array}$ \\
\hline
\end{tabular}

52 Congreso de la República de Colombia, Ley 418 de 1997.

53 Colombia, Presidencia de la República, Decreto 2816 de 2006, "Por el cual se diseña y reglamenta el Programa de protección de derechos humanos del Ministerio del Interior y de Justicia y se adoptan otras disposiciones" (Bogotá: Diario Oficial núm. 46.368, 22 de agosto de 2006).

54 Colombia, Ministerio del Interior, Resolución 2138 de 2006 (Bogotá, 30 de junio de 2006).

55 Colombia, Presidencia de la República, Decreto 4100 de 2011, "Por el cual se crea y organiza el sistema nacional de derechos humanos y derecho internacional humanitario, se modifica la comisión intersectorial de derechos humanos y derecho internacional humanitario y se dictan otras disposiciones" (Bogotá: Diario Oficial núm. 48.241, 2 de noviembre de 2011).

56 Colombia, Presidencia de la República, Decreto 4065 de 2011, "Por el cual se crea la Unidad Nacional de Protección (UNP), se establecen su objetivo y estructura" (Bogotá: Diario Oficial núm. 48.239, 31 de octubre de 2011).

57 Colombia, Presidencia de la República, Decreto 4912 de 2011, "Por el cual se organiza el Programa prevención y protección de los derechos a la vida, la libertad, la integridad y la seguridad de personas, grupos y comunidades del Ministerio del Interior y de la Unidad Nacional de Protección" (Bogotá: Diario Oficial núm. 48.294, 26 de diciembre de 2011).

58 Colombia, Presidencia de la República, Decreto 1066 de 2015, "Por medio del cual se expide el Decreto único reglamentario del sector administrativo del interior” (Bogotá: Diario Oficial núm. 49.523, 26 de mayo de 2015). 


\begin{tabular}{|l|l|}
\hline Resolución 1085 de $2015^{59}$ & $\begin{array}{l}\text { Protocolo para implementar la ruta de protección colectiva del Programa de } \\
\text { prevención y protección del Ministerio del Interior y la Unidad Nacional de } \\
\text { Protección. }\end{array}$ \\
\hline Circular 035 de $2016^{60}$ & $\begin{array}{l}\text { Referida al reconocimiento, al respeto y a la garantía de la labor de los defensores, } \\
\text { los líderes y las lideresas sociales, étnicas y populares de los derechos humanos. }\end{array}$ \\
\hline Decreto 1314 de $2016^{61}$ & $\begin{array}{l}\text { Crea la Comisión intersectorial de garantías para las mujeres lideresas y } \\
\text { defensoras de los derechos humanos. }\end{array}$ \\
\hline Decreto 1581 de $2017^{62}$ & $\begin{array}{l}\text { Promueve el respeto y la garantía de los derechos a la vida, integridad, libertady y } \\
\text { seguridad de todas las personas, grupos y comunidades en el territorio nacional. }\end{array}$ \\
\hline
\end{tabular}

Fuente: elaboración propia

El Ministerio Público, conformado por la Procuraduría General de la Nación, la Defensoría del Pueblo y las Personerías Municipales, ha adoptado medidas para proteger a los defensores de DDHH, en cumplimiento de la directriz instaurada por la Constitución Política de 1991 en su Artículo 118.63 De esta manera, ha adoptado (Tabla 8):

Colombia, Ministerio del Interior, Resolución 1085 de 2015 (Bogotá, 21 de agosto de 2015).

60 Colombia, Ministerio del Interior, Circular 035 de 2016 (Bogotá, 20 de junio de 2016).

61 Colombia, Presidencia de la República, Decreto 1314 de 2016, "Por el cual se crea la comisión intersectorial de garantías para las mujeres lideresas y defensoras de los derechos humanos" (Bogotá: Diario Oficial núm. 49.961, 10 de agosto de 2016).

62 Colombia, Presidencia de la República, Decreto 1581 de 2017, "Por el cual se adiciona el Título 3 a la Parte 4, del Libro 2 del Decreto 1066 de 2015, Decreto único reglamentario del sector administrativo del interior, para adoptar la política pública de prevención de violaciones a los derechos a la vida, integridad, libertad y seguridad de personas, grupos y comunidades, y se dictan otras disposiciones" (Bogotá: Diario Oficial núm. 50.370, 28 de septiembre de 2017).

63 Al Ministerio Público le corresponde la guarda y promoción de los derechos humanos y la protección del interés público. 
Tabla 8. Deberes legales del Estado para proteger a los defensores de derechos humanos

\begin{tabular}{|l|l|}
\hline Decreto 262 de $2000^{64}$ & $\begin{array}{l}\text { Deber de la entidad adelantar acciones preventivas frente a la violación de los } \\
\text { derechos humanos, así como investigar tanto la acción como la omisión de } \\
\text { servidores públicos cuando, con su actuar, afecten su función, al vulnerar los } \\
\text { derechos fundamentales de los ciudadanos. }\end{array}$ \\
\hline Directiva 012 del $2010^{65}$ & $\begin{array}{l}\text { Directrices para garantizar el derecho de los defensores de DDHH para ejercer } \\
\text { su labor. }\end{array}$ \\
\hline $\begin{array}{l}\text { Directiva } 002 \text { del } 14 \text { de junio } \\
\text { de } 2017^{66}\end{array}$ & $\begin{array}{l}\text { Lineamientos para la protección efectiva de los derechos de los defensores de } \\
\text { DDHH y sus organizaciones e integrantes de los movimientos sociales y políticos, } \\
\text { así como lideresas y líderes políticos y sociales y sus organizaciones. }\end{array}$ \\
\hline Ley 1448 de $2011^{67}$ & $\begin{array}{l}\text { Creación del Sistema de información de alertas tempranas (Sisat), a cargo de } \\
\text { la Defensoría, con el propósito de cumplir con el deber de seguimiento a la } \\
\text { evolución del riesgo, al impacto y a los resultados de la respuesta institucional } \\
\text { ante las violaciones de derechos humanos y derecho internacional humanitario. }\end{array}$ \\
\hline
\end{tabular}

Fuente: elaboración propia

Si bien puede verse que existen entidades del orden nacional encargadas de velar por la protección de los derechos humanos y, en consecuencia, a los mismos defensores, las cifras expuestas reflejan la ineficacia de las políticas adoptadas por el Estado colombiano. En cambio, la protección judicial que debería brindar el Estado al defensor de DDHH debería basarse en dos puntos fundamentales: la primera, en la que los mecanismos y recursos que ofrecen los ordenamientos jurídicos de los Estados no deben ser usados como formas de hostigamiento a los defensores, dada la actividad lícita que ellos desarrollan y sus efectos en el Estado de Derecho; la segunda, que la interposición por parte del afectado de recursos ágiles, sencillos y efectivos para garantizar el goce de derechos se relaciona intrínsecamente con su vulnerabilidad, esto es, la inminencia de un ataque potencialmente peligroso. ${ }^{68}$

No basta con que se creen Leyes, decretos, reglamentos, comisiones, programas, campañas publicitarias o cualquier otra iniciativa, si no contienen medidas sustentables

${ }_{64}$ Colombia, Presidencia de la República, Decreto 262 de 2000, "Por el cual se modifican la estructura y la organización de la Procuraduría General de la Nación y del Instituto de Estudios del Ministerio Público; el régimen de competencias interno de la Procuraduría General; se dictan normas para su funcionamiento; se modifica el régimen de carrera de la Procuraduría General de la Nación, el de inhabilidades e incompatibilidades de sus servidores y se regulan las diversas situaciones administrativas a las que se encuentren sujetos" (Bogotá: Diario Oficial núm. 43.904, 22 de febrero de 2000).

65 Colombia, Procuraduría General de la Nación, Directiva 012 de 2010 (Bogotá, 27 de julio de 2010).

66 Colombia, Procuraduría General de la Nación, Directiva 002 de 2017 (Bogotá, 14 de junio de 2017).

67 Congreso de la República de Colombia, Ley 1448 de 2011, "Por la cual se dictan medidas de atención, asistencia y reparación integral a las víctimas del conflicto armado interno y se dictan otras disposiciones" (Bogotá: Diario Oficial núm. 48.096, 10 de junio de 2011).

68 Comisión Interamericana de Derechos Humanos, Segundo informe, 113-118. 
en la realidad que hoy viven los defensores de derechos humanos en Colombia. De nada sirve el compromiso del Gobierno, si no coordina con las comunidades que sufren los embates de la violencia existente en el país. Asimismo, las medidas adoptadas en la jurisdicción interna deben guardar estrecha relación con el control de convencionalidad y velar por la eficacia de tales disposiciones, para la tutela judicial efectiva de los derechos humanos.

\section{Conclusiones}

Del análisis de los patrones de caracterización del defensor de DDHH, del marco normativo vigente, de la situación actual de estas personas en el ejercicio de derechos colectivos — bien sea para hacerlos valer o para reivindicarlos en favor de grupos sociales perjudicados por condiciones desiguales, adversas y discriminatorias- y de las medidas que el Estado colombiano ha adoptado para mitigar la situación de vulnerabilidad del defensor de DDHH o líder social, se presentan algunos aspectos que demuestran el grado de cohesión entre leyes, políticas y aplicación de mecanismos de protección.

En primer lugar, se ha aclarado que el defensor de DDHH puede ser un servidor público, una persona particular o una organización no gubernamental, como persona jurídica. No obstante, se ha puesto especial atención en los particulares, toda vez que su participación voluntaria en el ejercicio democrático constituye un pilar para las acciones de control que ejercen en procura de la garantía del Estado de derecho.

Entre las diversas categorías de defensores de DDHH se han destacado los defensores del derecho a la tierra y al territorio, así como los líderes comunitarios, incluidos los afrodescendientes e indígenas como las personas con mayor peligro de recibir un ataque por ejercer actividades de la defensa de los derechos colectivos e individuales. El grado de peligro al que se exponen los defensores de DDHH es inversamente proporcional a la percepción de "tranquilidad" que se vive en algunas regiones del país tras la finalización de las negociaciones de paz con las FARC-EP y la implementación de los acuerdos de paz, aún en proceso.

Se observa con preocupación que el número de atentados contra los defensores, muchos de los cuales concluyeron en homicidio, se concentran en regiones donde la influencia de diversos actores armados ha permanecido durante más de cuatro décadas; que pone de manifiesto la inoperancia, la negligencia y la falta de presencia del Estado que, lejos de protegerlos, los discrimina, los estigmatiza y les 
obstaculiza el acceso a mecanismos de protección que garanticen el ejercicio de un derecho legítimo.

Los mecanismos de protección, incorporados por nuevas leyes y decretos, se quedan en letra muerta, pues la inacción del Estado, las relaciones de control territorial y económico y, en algunos casos, la aquiescencia de las autoridades, desvirtúan todo un engranaje de medidas que, aplicadas en forma efectiva, permitirían garantizar con eficiencia la seguridad de los defensores, la legitimación de su trabajo como protección de la sociedad y la institucionalidad del Estado, así como el cumplimiento de los fines del Estado, contemplados en el Artículo 2 constitucional y las obligaciones internacionales contenidas en los Artículos 1 y 2 de la CADH y otros tratados internacionales.

\section{Referencias}

Agencia Nacional de Tierras. "La Agencia", http://www.agenciadetierras.gov.co, (acceso julio 16, 2018).

Aguilar Cavallo, Gonzalo y Rebecca Steward. "El defensor del pueblo latinoamericano como institución independiente de promoción y protección de los derechos humanos: referencia especial a la situación actual en Chile". Revista de derecho 15, núm. 2 (abril 2008): 21-66. https://www.redalyc.org/Artículo.oa?id=371041323002 (acceso julio $16,2018)$.

Amnistía Internacional. "Defensores y defensoras de los derechos humanos". https://www. es.amnesty.org/en-que-estamos/temas/defensores/ (acceso agosto 7, 2018).

Amnistía Internacional. Informe 2017/2018 Amnistía Internacional: la situación de derechos humanos en el mundo. Londres: Autor, 2018.

Ansolabehere, Karina y Luis Daniel Vásquez. "De la injusticia a los derechos: momentos en la construcción de identidad de defensores de derechos humanos. El caso de México". Estudios sociológicos 35, núm. 105 (septiembre-diciembre 2017): 517-545, http://www.scielo.org.mx/pdf/es/v35n105/2448-6442-es-35-105-0517.pdf (acceso julio 16, 2018).

Chacón Triana, Nathalia María. Acceso al Sistema interamericano de derechos humanos. Perspectiva jurisprudencial. Bogotá: Ibáñez, 2018.

Colombia, Ministerio de Defensa Nacional. Directiva ministerial 09 de 2003. Bogotá, 8 de julio de 2003.

Colombia, Ministerio del Interior. Circular 035 de 2016. Bogotá, 20 de junio de 2016.

Colombia, Ministerio del Interior. Circular CRI01 de 2018. Bogotá, 4 de agosto de 2018.

Colombia, Ministerio del Interior. Resolución 1085 de 2015. Bogotá, 21 de agosto de 2015. 
Colombia, Ministerio del Interior. Resolución 2138 de 2006. Bogotá, 30 de junio de 2006. Colombia, Presidencia de la República. Decreto 1066 de 2015, "Por medio del cual se expide el Decreto único reglamentario del sector administrativo del interior". Bogotá: Diario Oficial núm. 49.523, 26 de mayo de 2015.

Colombia, Presidencia de la República. Decreto 1314 de 2016, "Por el cual se crea la Comisión intersectorial de garantías para las mujeres lideresas y defensoras de los derechos humanos". Bogotá: Diario Oficial núm. 49.961, 10 de agosto de 2016.

Colombia, Presidencia de la República. Decreto 1386 de 2002, "Por el cual el cual se dictan medidas para brindar protección a alcaldes, concejales y personeros municipales". Bogotá: Diario Oficial núm. 44.861, 10 de julio de 2002.

Colombia, Presidencia de la República. Decreto 1581 de 2017, "Por el cual se adiciona el Título 3 a la Parte 4, del Libro 2 del Decreto 1066 de 2015, Decreto único reglamentario del sector administrativo del interior, para adoptar la política pública de prevención de violaciones a los derechos a la vida, integridad, libertad y seguridad de personas, grupos y comunidades, y se dictan otras disposiciones". Bogotá: Diario Oficial núm. 50.370, 28 de septiembre de 2017.

Colombia, Presidencia de la República. Decreto 1592 de 2000, "Por el cual se reglamenta el artículo 6 de la Ley 199 de 1995”. Bogotá: Diario Oficial núm. 44.139, 18 de agosto de 2000 .

Colombia, Presidencia de la República. Decreto 262 de 2000, "Por el cual se modifican la estructura y la organización de la Procuraduría General de la Nación y del Instituto de Estudios del Ministerio Público; el régimen de competencias interno de la Procuraduría General; se dictan normas para su funcionamiento; se modifica el régimen de carrera de la Procuraduría General de la Nación, el de inhabilidades e incompatibilidades de sus servidores y se regulan las diversas situaciones administrativas a las que se encuentren sujetos". Bogotá: Diario Oficial núm. 43.904, 22 de febrero de 2000.

Colombia, Presidencia de la República. Decreto 2788 de 2003, "Por el cual se unifica y reglamenta el Comité de reglamentación y evaluación de riesgos de los programas de protección de la dirección de derechos humanos del Ministerio del Interior y de Justicia”. Bogotá: Diario Oficial núm. 45.329, 2 de octubre de 2003.

Colombia, Presidencia de la República. Decreto 2816 de 2006, "Por el cual se diseña y reglamenta el Programa de protección de derechos humanos del Ministerio del Interior y de Justicia y se adoptan otras disposiciones". Bogotá: Diario Oficial núm. 46.368, 22 de agosto de 2006.

Colombia, Presidencia de la República. Decreto 4065 de 2011, "Por el cual se crea la Unidad Nacional de Protección (UNP), se establecen su objetivo y estructura". Bogotá: Diario Oficial núm. 48.239, 31 de octubre de 2011. 
Colombia, Presidencia de la República. Decreto 4100 de 2011, "Por el cual se crea y organiza el sistema nacional de derechos humanos y derecho internacional humanitario, se modifica la comisión intersectorial de derechos humanos y derecho internacional humanitario y se dictan otras disposiciones". Bogotá: Diario Oficial núm. 48.241, 2 de noviembre de 2011.

Colombia, Presidencia de la República. Decreto 4912 de 2011, "Por el cual se organiza el Programa prevención y protección de los derechos a la vida, la libertad, la integridad y la seguridad de personas, grupos y comunidades del Ministerio del Interior y de la Unidad Nacional de Protección”. Bogotá: Diario Oficial núm. 48.294, 26 de diciembre de 2011.

Colombia, Presidencia de la República. Decreto 660 de 2018, "Por el cual se adiciona el Capítulo 7, del Título 1, de la Parte 4, del Libro 2 del Decreto 1066 de 2015, Único Reglamentario del Sector Administrativo del Interior, para crear y reglamentar el Programa integral de seguridad y protección para comunidades y organizaciones en los territorios; y se dictan otras disposiciones”. Bogotá: Diario Oficial núm. 50.567, 17 de abril de 2018.

Colombia, Presidencia de la República. Decreto 978 de 2000, "Por el cual se crea el Programa especial de protección integral para dirigentes, miembros y sobrevivientes de la Unión Patriótica y del Partido Comunista Colombiano". Bogotá: Diario Oficial núm. 44.033, 1 de junio de 2000.

Colombia, Presidencia de la República. Directiva presidencial 07 de 1999. Bogotá: 9 de septiembre de 1999.

Colombia, Procuraduría General de la Nación. Directiva 002 de 2017. Bogotá: 14 de junio de 2017.

Colombia, Procuraduría General de la Nación. Directiva 012 de 2010. Bogotá: 27 de julio de 2010.

Colombia, Procuraduría General de la Nación. Violencia contra los defensores de derechos territoriales en Colombia. Bogotá: Procuraduría General de la Nación, 2018.

Comisión Interamericana de Derechos Humanos. "Informe sobre la situación de las defensoras y los defensores de derechos humanos en las Américas". http://www.cidh. org/countryrep/Defensores/defensoresindice.htm (acceso julio 16, 2018).

Comisión Interamericana de Derechos Humanos. "Pronunciamiento de la Comisión Interamericana de Derechos Humanos sobre la aplicación y el alcance de la ley de justicia y paz en la República de Colombia”. http:/www.cidh.org/countryrep/ Colombia2006sp/pronunciamiento.8.1.06esp.htm (acceso julio 16, 2018).

Comisión Interamericana de Derechos Humanos. Segundo informe sobre la situación de las defensoras y los defensores de derechos humanos en las Américas. Washington: Organización de Estados Americanos, 2011. 
Congreso de la República de Colombia. Ley 1448 de 2011, "Por la cual se dictan medidas de atención, asistencia y reparación integral a las víctimas del conflicto armado interno y se dictan otras disposiciones". Bogotá: Diario Oficial núm. 48.096, 10 de junio de 2011. Congreso de la República de Colombia. Ley 1957 de 2019, "Estatutaria de la Administración de Justicia en la Jurisdicción Especial para la Paz". Bogotá: Diario Oficial núm. 50.976, 6 de junio de 2019.

Congreso de la República de Colombia. Ley 418 de 1997, "Por la cual se consagran unos instrumentos para la búsqueda de la convivencia, la eficacia de la justicia y se dictan otras disposiciones". Bogotá: Diario Oficial núm. 43.201, 26 de diciembre de 1997.

Congreso de la República de Colombia. Ley 489 de 1998, "Por la cual se dictan normas sobre la organización y funcionamiento de las entidades del orden nacional, se expiden las disposiciones, principios y reglas generales para el ejercicio de las atribuciones previstas en los numerales 15 y 16 del artículo 189 de la Constitución Política y se dictan otras disposiciones". Bogotá: Diario Oficial núm. 43.464, 30 de diciembre de 1998.

Corte Interamericana de Derechos Humanos. Caso Baena Ricardo y otros Vs. Panamá. Sentencia del 28 de noviembre de 2003.

Corte Interamericana de Derechos Humanos. Caso Cinco pensionistas Vs. Perú. Sentencia del 28 de febrero de 2003.

Corte Interamericana de Derechos Humanos. Caso Yarce y otras Vs. Colombia. Sentencia del 22 de noviembre de 2016.

Corte Interamericana de Derechos Humanos. Control de convencionalidad: cuadernillo de jurisprudencia de la Corte Interamericana de Derechos Humanos No. 7. San José: Organización de Estados Americanos, 2015.

Cubides Cárdenas, Jaime y Tania Giovanna Vivas Barrera. "La justicia transicional y el rol de la Corte Interamericana de Derechos Humanos” en Fundamentación y aplicabilidad de la justicia transicional en Colombia, editado por Jaime Cubides Cárdenas, 67-98. Bogotá: Universidad Católica de Colombia, 2016.

Federación Internacional por los Derechos Humanos. "Defensores de derechos humanos". https://www.fidh.org/es/temas/defensores-de-derechos-humanos/ (acceso agosto 2, 2018).

Fundación Heinrich Böll. "Informe especial de derechos humanos: situación de lideresas y líderes sociales, de defensoras y defensores de derechos humanos y de excombatientes de las FARC-EP y sus familiares". Ideas verdes, núm. 8 (junio 2018): 1-68. https:// co.boell.org/sites/default/files/20180629_ideas_verdes_8_web.ok_.pdf (acceso julio 16, 2018).

Gobierno Nacional y Fuerzas Armadas Revolucionarias de Colombia-Ejército del Pueblo. Acuerdo final para la terminación del conflicto y la construcción de una paz estable y duradera. Bogotá, 24 de noviembre de 2016. 
González León, Luis y Gilberto Ramírez. "Los derechos humanos de las víctimas: una perspectiva desde las responsabilidades del Estado y la sociedad civil" en Los derechos humanos a debate. Perspectivas desde el derecho internacional, editado por Gilberto Ramírez Huertas, 105-112. Bogotá: Universidad Católica de Colombia, 2017.

Instituto de Estudios para el Desarrollo y la Paz. Informe líderes y defensores de DDHH asesinados al 26 de julio de 2019. Bogotá, 23 de julio de 2019.

López, Jairo Antonio. "Movilización y acción colectiva por los derechos humanos en la paradoja de la institucionalización”. Estudios políticos, núm. 51 (julio-diciembre 2017): 57-78. https://www.redalyc.org/Artículo.oa?id=16452081004 (acceso julio 16, 2018).

Mínguez Alcaide, Xavier. "Conflicto y paz en Colombia. Significados en organizaciones defensoras de los derechos humanos". Revista de paz y conflictos 8, núm. 1 (2015): 179-196, https://dialnet.unirioja.es/descarga/Artículo/5117125.pdf (acceso julio 16, 2018).

Montoya Ruiz, Sandra, John Castro Ortiz y Jaime Cubides Cárdenas. "Elementos jurídicos y de legitimación para acuerdos de paz con miras al posconflicto" en Desafíos contemporáneos de la protección de los derechos humanos en el Sistema Interamericano, editado por Jaime Cubides Cárdenas, 85-101. Bogotá: Universidad Católica de Colombia, 2017.

Negret Mosquera, Carlos Alfonso. "El riesgo de los defensores de derechos humanos merece mayor atención del Estado". http://www.defensoria.gov.co/es/nube/ comunicados/7716/\%E2\%80\%9CEl-riesgo-de-los-defensores-de-derechos-humanosmerece-mayor-atenci\%C3\%B3n-del-Estado\%E2\%80\%9D-Defensor-Defensordel-Pueblo-Carlos-Negret-Defensor\%C3\%ADa-derechos-humanos.htm (acceso julio 16, 2018).

Observatorio de Derechos Humanos. "Acerca de nosotros". https://www.hrw.org/es (acceso julio 16, 2018).

Oficina del Alto Comisionado de las Naciones Unidas para los Derechos Humanos. Los defensores de los derechos humanos: protección del derecho a defender los derechos humanos. Nueva York: ONU, 2018.

Oficina del Alto Comisionado de las Naciones Unidas para los Derechos Humanos. Informe del Alto Comisionado de las Naciones Unidas para los derechos humanos sobre la situación de derechos humanos en Colombia durante el año 2016. Bogotá: OACNUDH, 2017.

Oficina del Alto Comisionado de las Naciones Unidas para los Derechos Humanos. Informe del Alto Comisionado de las Naciones Unidas para los derechos humanos sobre la situación de derechos humanos en Colombia durante el año 2017. Bogotá: OACNUDH, 2018.

Oficina del alto comisionado de las Naciones Unidas para los derechos humanos. "¿Quiénes somos?". https://www.ohchr.org/sp/aboutus/Pages/WhoWeAre.aspx (acceso julio 16, 2018). 
Oficina del alto comisionado de las Naciones Unidas para los derechos humanos. "Sobre los defensores de los derechos humanos". https:/www.ohchr.org/sp/issues/srhrdefenders/ pages/defender.aspx (acceso julio 16, 2018).

Organización de las Naciones Unidas [ONU]. La Declaración de los defensores de los derechos humanos. Nueva York, 8 de marzo de 1999.

Organización de los Estados Americanos. Convención americana de derechos humanos. San José, 22 de noviembre de1969.

Programa Somos Defensores. Contra las cuerdas: informe anual 2016 sistema de información sobre agresiones contra defensores de DDHH en Colombia SIADDHH. Bogotá: Factoría Gráfica, 2017.

Programa Somos Defensores. La naranja mecánica: informe anual 2018 sistema de información sobre agresiones contra personas defensoras de derechos en Colombia SIADDHH. Bogotá: El búho, 2019.

Programa Somos Defensores. Piedra en el zapato: informe anual 2017 sistema de información sobre agresiones contra defensores y defensoras de DD.HH. en Colombia. Bogotá: Cimaz, 2018.

Programa Somos Defensores. Un canto final: manual de protección para defensores y defensoras de derechos humanos en Colombia. Bogotá: Alta Voz Ediciones, 2010.

Programa Somos Defensores. Un canto para persistir: manual de protección para defensores y defensoras de derechos humanos en Colombia. Bogotá: Alta Voz, 2010.

República de Colombia. Constitución Política. Bogotá: Legis, 1991.

Roncancio Bedoya, Andrés Felipe, Víctor Julián Moreno Mosquera y Pablo Daniel Hurtado Quintero. "El papel del defensor de derechos humanos como parresiasta: desafíos para la construcción de paz en el proceso de finalización del conflicto armado en Colombia”. Vía Iuris, núm. 21 (julio-diciembre 2016): 165-181, https://www.redalyc. org/pdf/2739/273950435010.pdf (acceso julio 16, 2018).

Tafur Charry, Magda Paola. "El Precedente jurisprudencial" en Precedente jurisprudencial en materia de justicia transicional, editado por Magda Paola Tafur Charry, 68. Bogotá: Universidad Católica de Colombia, 2016.

Vieira, Oscar Vilhena. "La desigualdad y la subversión del Estado de derecho". SUR - Revista internacional de derechos humanos 4, núm. 6 (2007): 28-51, http://www.scielo.br/pdf/ sur/v4n6/es_a03v4n6.pdf (acceso julio 16, 2018). 